\title{
Erratum: Alves, J., et al. Correlations between Basal Trace Minerals and Hormones in Middle and Long-Distance High-Level Male Runners. International Journal of Environmental Research and Public Health 2020, 17, 9473
}

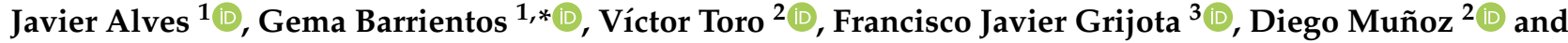 \\ Marcos Maynar ${ }^{2}$ (D)
}

check for updates

Citation: Alves, J.; Barrientos, G.; Toro, V.; Grijota, F.J.; Muñoz, D.; Maynar, M. Erratum: Alves, J., et al. Correlations between Basal Trace Minerals and Hormones in Middle and Long-Distance High-Level Male Runners. International Journal of Environmental Research and Public Health 2020, 17, 9473. Int. J. Environ. Res. Public Health 2021, 18, 2289. https://doi.org/10.3390/ijerph18052289

Received: 20 February 2021 Accepted: 22 February 2021 Published: 25 February 2021

Publisher's Note: MDPI stays neutral with regard to jurisdictional claims in published maps and institutional affiliations.

Copyright: (c) 2021 by the authors. Licensee MDPI, Basel, Switzerland. This article is an open access article distributed under the terms and conditions of the Creative Commons Attribution (CC BY) license (https:/ / creativecommons.org/licenses/by/ $4.0 /)$.
1 Department of Sport Science, Faculty of Education, Pontifical University of Salamanca, C/Henry Collet, 52-70, CP, 37007 Salamanca, Spain; fjalvesva@upsa.es

2 Department of Physiology, Faculty of Sports Science Faculty, University of Extremadura, University Avenue, s/n CP, 10003 Cáceres, Spain; vtororom@alumnos.unex.es (V.T.); diegomun@unex.es (D.M.); mmaynar@unex.es (M.M.)

3 Department of Education, Faculty of Language and Education, Antonio de Nebrija University, C/Del Hostal, 28248 Hoyo de Manzanares, Madrid, Spain; fgrijota@nebrija.es

* Correspondence: gbarrientosvi@upsa.es; Tel.: +34-923-125-027

The authors wish to correct the following erratum in this paper [1].

The fourth author's affiliation is not correct. It should read:

1. Department of Sport Science, Faculty of Education, Pontifical University of Salamanca, C/Henry Collet, 52-70, CP, 37007 Salamanca, Spain; fjalvesva@upsa.es (J.A.)

2. Department of Physiology, Faculty of Sports Science Faculty, University of Extremadura, University Avenue, s/n CP, 10003 Cáceres, Spain; vtororom@alumnos.unex.es (V.T.); diegomun@unex.es (D.M.); mmaynar@unex.es (M.M.)

3. Department of Education, Faculty of Language and Education. Antonio de Nebrija University, C/Del Hostal, 28248 Hoyo de Manzanares, Madrid, Spain; fgrijota@nebrija.es (F.J.G.)

Funding: This research received no external funding.

Institutional Review Board Statement: This research was conducted under the Helsinki Declaration ethical guidelines, updated at the World Medical Assembly in Fortaleza in 2013 for research with human participants, and the protocol was approved by the Ethics Committee of the University of Extremadura (52/2012).

Informed Consent Statement: Informed consent was obtained from all subjects involved in the study.

Data Availability Statement: Data supporting reported results can be found in the next link. https:/ / www.mdpi.com/1660-4601/17/24/9473.

Conflicts of Interest: The authors declare no conflict of interest.

\section{Reference}

1. Alves, J.; Barrientos, G.; Toro, V.; Grijota, F.J.; Muñoz, D.; Maynar, M. Correlations between Basal Trace Minerals and Hormones in Middle and Long-Distance High-Level Male Runners. Int. J. Environ. Res. Public Health 2020, 17, 9473. [CrossRef] [PubMed] 